\title{
Socio-Economic and Constraint Status Assessment of Krishi Vigyan Kendra Training Programmes in Nagaland
}

\author{
Imsunaro Jamir and Amod Sharma* \\ Department of Agricultural Economics, Nagaland University SASRD, Medziphema Campus, \\ District: Dimapur - 797 106, Nagaland, India \\ *Corresponding author
}

\begin{tabular}{|c|}
\hline Keywords \\
\hline $\begin{array}{l}\text { KVK, Impact, Training, } \\
\text { Capital, Formation, } \\
\text { Assessment, Programme, } \\
\text { Yield, Income, } \\
\text { Employment }\end{array}$ \\
\hline Article Info \\
\hline $\begin{array}{l}\text { Accepted: } \\
15 \text { October } 2018 \\
\text { Available Online: } \\
10 \text { November } 2018\end{array}$ \\
\hline
\end{tabular}

A B S T R A C T
The present study on access the impact of Krishi Vigyan Kendra (KVK's) for conducting the training programmes in their respective district of the Nagaland state during the year 2012-13 to 2016-17 (five years) and also to assess the impact of income as well as employment generated for that purpose it was categorized into two groups viz., adopted and non-adopted villages ( 80 respondents to each category which make a total of 160 respondents). To achieve the objectives of the present study a multi stage purpose random sampling methods was adopted. Further the an attempt is made to identify the constraints faced by the KVK's adopted for adopting the different scheme / programme implemented under different constraints head wise viz., technological, economical, institutional and infra-structural facilities faced by them are presented in the descending order of their relative importance in table. The foremost constraints they faced is technological constraints so the frequency, simple percentage and then it has been ranked using the Garrett's ranking technique and the analytical findings it was found almost similar across various farm size groups so it was recorded as average / overall views. Therefore, constraints are not discussed according to different size group.

\section{Introduction}

Nagaland, the $16^{\text {th }}$ State of the Indian Union, came into being on $01^{\text {st }}$ December 1963. Nagaland with a geographical area of about $16,579 \mathrm{Sq}$. Km. lies between $25^{\circ} 60^{\prime}$ and $27^{\circ} 40^{\prime}$ North latitude and $93^{\circ} 20^{\prime}$ and $95^{\circ} 15^{\prime}$ East longitude. The state is bounded by Assam in the North and West, by Myanmar and Arunachal Pradesh in the East and by Manipur in the South. Nagaland, being one of the "eight Sisters" commonly called as the NorthEastern Region including Sikkim, is a land of lush green forests, rolling Mountains, enchanting valleys, swift flowing streams and of beautiful landscape. The inhabitants of Nagaland are almost entirely tribal with distinctive dialects and cultural features (Annon, 2017).

The state is predominantly rural with 82.26 per cent of population living in villages. The state comprises of 11 administrative headquarters with 52 blocks and 1,278 inhabited villages. Each district has generally predominance / concentration of one of the 
major / minor tribe of the state, thereby making districts distinct in their linguistic, cultural, traditional and socio-political characteristics. The topography of Nagaland is much dissected, full of hill ranges, which break into a wide chaos of spurs and ridges. The terrain is mountainous covered by rich and varied biodiversity of flora and fauna. It is one of the 25 hot spots of the world with respect to its biological diversity, and hence can be termed as the state of true Mega biodiversity. The state houses the confluence of flora and fauna of the neighbouring regions. Geographically, the state largely has vast undulating terrain and hilly landscape and some low lying areas giving rise to a very conducive climate with presence of perennial water and moisture for truly rich variety of flora and fauna (Anon., 2017).

Agriculture is one of the significant contributors to the Net State Domestic Product and is the largest employer of the working force in the state. Though the dependency of employment on agriculture has declined from as high as 96.50 per cent in the 1950 s to about 68.00 per cent in 2000 , it continues to be the main source of livelihood. Shifting and terraced cultivations remains the dominant forms of land use practice in the state. The traditional form of shifting cultivation i. e; jhum, is the method of cultivation that is widely practiced across Nagaland. Jhum occupies about 90.00 per cent of the area under agriculture. Terraced cultivation is confined largely to the districts of Kohima, Dimapur, Tuensang, Peren, Phek and Wokha. The single cropping system is prevalent in the state resulting in low cropping intensity. Multiple cropping is yet to be practiced by farmers except in very small and negligible pockets (Singh et al., 2007).

Since KVK has taken up good step in this direction and results are very encouraging since 1988-1989 in Nagaland. Therefore, it is foremost need to evaluate the performance of KVK by this investigation; so to access the impact or benefits gained by the farming community in term of income and employment can be justified. In the region farmers possess very small size of holdings and family labour (male, female \& children) remains underemployed. Seasonal employment is a chronic affair. Hence farmer needs subsidiary occupation, which may lead to generate additional employment and income as well as infrastructure through KVK training, so that government as well as local inhabitants should give more attention for implementation of $\mathrm{KVK}$ programme in the region, as the scheme has been implemented in all eleven district of Nagaland State (Walling et al., 2007).

The programmes of each KVK cover viz; training, on-farm trials, frontline demonstrations, agricultural extension and livelihood activities. Keeping in view the above fact, the present study is undertaken, with the following objectives viz; (i) to study the socio-economic status of the farmers, and (ii) to suggests the constraints in disseminating knowledge by the KVK's.

\section{Materials and Methods}

The present study is to access the socioeconomic and constraints faced during the KVK's for disseminating the agriculture technology to the farming community in Nagaland state, which is working as per the guideline of Central Government with the help of Ministry of Agriculture, Government of India. The sampling design and analytical techniques to be used in the light of objectives laid down for the study have been presented under the following sub-headings (Dubey et al., 2007).

The develop projects require long period of time to reap the benefit, therefore for 
economic appraisal of development, it is essential that the scheme has been in operation for quite some time. Since the intensive KVK started in 1988-89, so it is worth -while to study its impact. Since the data of the initial period cannot be compared with the data of recent years, it is more scientific and practical to compare the economy of the beneficiaries / trainees covered in the area of KVK schemes.

The KVK was launched in 1988-89 in all 11 districts viz., Dimapur, Kohima, Kheprie, Longleng, Mokokchung, Mon, Phek, Peren, Tuensang, Wokha and Zunhebuto of Nagaland, out of these districts two district viz., Mokokchung and Zunhebuto districts of Nagaland have been selected because of the fact that it is expected to provide all the relevant information and hence can conveniently be obtained for conducting this study. The project area also has a good network of infrastructure and allied activities related to the scheme such as development agencies, nationalized banks, well-established marketing and communication facilities etc. Keeping all the above facts, both districts of Nagaland are therefore purposively selected to conduct this study. (a) Mokokchung district: Mokokchung district is situated in the Southeastern part of Nagaland, bounded by Wokha districts in the North, Assam state in the South and Zunheboto district in the West. Earlier a part of Kohima district, it was made a separate district on December 01, 1969. It is inhabited by the mixed type of populations. It is a basically hill area district rich in agricultural and horticultural production base area and surrounded by river. Mokokchung is developed district of the State. (b) Zunhebuto district: Zunhebuto is one of the under developed district of Nagaland having a total geographical area of 1,36,455 ha. Zunhebuto District is bounded by the state of Assam to its north, Tuensang to its east, Mokokchung to its south and Wokha and Assam to its west, and lies between 93.53 and 94.53 degrees longitude and 25.56 degrees latitude. In this district all 4 types of agro-climatic conditions are present.

Two blocks from each district will be selected randomly for the present study as these blocks are well covered by KVK programme. Altogether eight villages were selected randomly from each district, while four villages from each block were selected and listed which would be obtained from the offices of SDO (Civil), R. D. block headquarter and other related offices. However, it is proposed to select four villages from each block randomly covered for KVK programme / schemes. After selection of the villages, a list of beneficiaries and nonbeneficiaries of KVK will be prepared from each of the selected village. In order to have representative sample from each village a sample of 20 numbers of cases of KVK, out of that 10 from beneficiaries and 10 from nonbeneficiaries will be drawn following the purposively random sampling method. This will result in selection of 160 respondents from 8 villages, out of which 80 will be beneficiaries of KVK schemes and 80 will be non-beneficiaries of KVK schemes.

\section{Results and Discussions}

Table 1 reveals the present status in the study areas, as 80 (50.00 per cent) numbers each of farmers / respondents were selected from the adopted and non-adopted of KVK's programme / training in the two selected categories, out of the total 160 (100.00 per cent) respondents selected for the present study the 100 (66.67 per cent) were received low training (up to 2) organised by the KVK's, while 20 (25.00 per cent) of the adopted KVK's were got low trainings and among the non-adopted of KVK all 80 (50.00 per cent) were get low trainings, respectively. Whereas 35 (43.75 per cent) were in medium range (3 to 5) of trainings and 25 (31.25 per 
cent) were got high range of trainings (6 and above), respectively.

Socio-economic conditions are an important parameter for determining the level of the farmer's knowledge and the managerial skills. Socio-economic variables are also an important parameter that determines the entrepreneurial development as any enterprise varies in their level and types of resources requirements. Hence, the socio-economic variables of the sample farm family for both KVK's adopted and non-adopted such as level of education, occupational pattern, cropping pattern and annual family income are discussed under the following heads. Similar studies carried out by Ahmad et al., (2012).

Table 2 reveals the age group of the farmers / respondents received the training under KVK's programme throughout the year in the study areas, as 80 (50.00 per cent) numbers each of respondents were selected from the adopted and non-adopted of KVK's programme in both the categories, out of the total 160 (100.00 per cent) respondents selected for the present study the 1 ( 0.62 per cent) were from voter age (up to 16) organised by the KVK's, it was found nil on adopted KVK's, while 1 (0.62 per cent) were among the non-adopted of KVK. On overall the young age (17 to 25 years) 4 (2.50 per cent) on overall, out of that all 1 ( 0.62 per cent) of KVK's adopted and it was found 3 (1.88 per cent) for non-adopted KVK's respondents.

On the middle age (26 to 35 years) 24 (15.00 per cent) on overall groups, 10 (6.25 per cent) organised by the KVK's and it was found 24 (15.00 per cent) on non-adopted KVK's, while 94 (58.75 per cent) were from mature age (36 to 59 years), 54 (33.75 per cent) were from adopted and 40 (25.000 per cent) were among the non-adopted of KVK. While on the overall the old age (60 and above) 37 (23.12 per cent), 15 (9.37 per cent) of KVK's adopted and it was found 22 (13.75 per cent) for non-adopted KVK's respondents, respectively. Similar studies carried out by Gaikwad et al., (2011).

Table 3 reveals the gender wise respondents received the training under KVK's programme throughout the year in the study areas, as 80 (50.00 per cent) numbers each of respondents were selected from the adopted and nonadopted of KVK's programme in both the categories, out of the total 160 (100.00 per cent) respondents selected for the present study the female on adopter were dominating as 36 (22.50 per cent) and non-adopter were 26 (16.25 per cent), which is an indication of women empowerment in the study area, while 54 (33.75 per cent) male were from nonadopter, followed by 44 (27.50 per cent) male was of adopter group, respectively. Similar studies carried out by (Sharma and Sharma, 2008; Pongener and Sharma, 2018).

Table 4 reveals the number of family member wise respondents received the training under KVK's programme throughout the year in the study areas, for the present study the 4 to 5 members was dominating as 44 (27.50 per cent), while non-adopter was found more as 45 (28.13 per cent), which is an good indication of small family size for the adopter in the study area, while being 4 (2.50 per cent) was 8 to 9 member of non-adopter, it was recorded as least 1 ( 0.62 per cent) on adopter group, respectively (Sharma, 2012). Table 5 reveals the education level of the respondents received the training under KVK's programme throughout the year in the study areas, for the present study the up to the high school education was dominating 36 (22.50 per cent) on non-adopter, followed by middle education on adopter with 32 (20.00 per cent), while it was found least as 4 (2.50 per cent) on nonadopter, whereas on adopter it was 5 (3.12 per cent) least as Graduate and above which is an indication of reverse co-relation of education, respectively (Walling and Sharma, 2015). 
Table 6 reveals the land holding of the respondents received the training under KVK's programme throughout the year in the study areas, for the present study the marginal was 45 (28.13 per cent) on adopter, followed on same group with 40 (25.00 per cent) on non-adopter, while it was found least as 5 (3.12 per cent) on adopter, whereas on nonadopter it was 6 (3.75 per cent) on large farm size group, respectively (Sharma, 2011).

Table 7 reveals the farm experience of the respondents received the training under KVK's programme throughout the year in the study areas, for the present study the high was 44 (27.50 per cent) on adopter, followed by medium with 38 (23.75 per cent) on nonadopter, while it was found to be least as 2 (1.25 per cent) on adopter, whereas on nonadopter it was 6 (3.75 per cent) both were found on low experience, respectively (Shuya and Sharma, 2014). Table 8 reveals that the occupation of selected sample respondents under KVK's programme in a year in the study areas, as 80 (50.00 per cent) numbers each of respondents were selected from the adopted and non-adopted of KVK's programme in both the categories, out of the total 160 (100.00 per cent) respondents selected for the present study the 35 (21.88 per cent) was adopted only agriculture, while nonadopter service and agriculture was founf as dominate 35 (21.88 per cent), respectively (Shuya and Sharma, 2018)

Table 9 reveals that the economic motivation under KVK's programme in a year in the study areas, as 80 (50.00 per cent) numbers each of respondents were selected from the adopted and non-adopted of KVK's programme in both the categories, out of the total 160 (100.00 per cent) respondents selected for the present study the 105 (58.33 per cent) were received low training (up to 12) organised by the KVK's, while 45 (56.25 per cent) of the adopted KVK's were got low trainings and among the non-adopted of KVK all 60 (37.50 per cent) were got low trainings, respectively. Whereas 25 (15.63 per cent) of KVK's adopted and 12 (7.50 per cent) nonadopted KVK's respondents were in medium range (13 to 18) of trainings and 10 (6.25 per cent) of KVK's adopted and 8 (4.44 per cent) of non-adopted KVK's were got high range of trainings (19 to 24), respectively (Rao et al., 2007).

Table 10 reveals that the scientific orientation by the KVK's programme in the study areas, as 80 (50.00 per cent) numbers each of respondents were selected from the adopted and non-adopted of KVK's programme in both the categories, out of the total 160 respondents selected for the present study the 105 were received low training (up to 12) organised by the KVK's, while 45 (56.25 per cent of the adopted KVK's were got low trainings and among the non-adopted of KVK all 60 (75.00 per cent) were got low trainings, respectively. Whereas 25 (31.25 per cent) of KVK's adopted and 12 (15.00 per cent) nonadopted KVK's respondents were in medium range (13 to 18$)$ of trainings and 10 (12.50 per cent) of KVK's adopted and 8 (10.00 per cent) of non-adopted KVK's were got high range of trainings (19 to 24), respectively (Kadam et al., 2012).

Table 11 reveals that the source of drinking water facilities availed by the selected sample respondents under KVK's programme in a year in the study areas, as 80 (50.00 per cent) numbers each of respondents were selected from the adopted and non-adopted of KVK's programme in both the categories, out of the total 160 (100.00 per cent) respondents selected for the present study the 80 (50.00 per cent) were enjoying the facilities as adopted it as cent percentage, while non-adopter 75 (46.88 per cent) were having the facilities of drinking water, respectively (Rao et al., 2012). 
Table.1 Location / area wise selected sample respondent

\begin{tabular}{|c|l|c|c|c|c|}
\hline S. N. & \multicolumn{1}{|c|}{ Response } & Total households & Adopted & Non-adopted & Overall \\
\hline A. & Mokokchung district: & & & \\
\hline 1. & Kubolong & $1826(31.98)$ & $20(12.50)$ & $20(12.50)$ & $40(25.00)$ \\
\hline 2. & $\begin{array}{l}\text { Ongpangkong } \\
\text { South }\end{array}$ & $2539(44.47)$ & $20(12.50)$ & $20(12.50)$ & $40(25.00)$ \\
\hline B. & Zunheboto district: & $962(16.68)$ & $20(12.50)$ & $20(12.50)$ & $40(25.00)$ \\
\hline 3. & Akuluto & $382(6.69)$ & $20(12.50)$ & $20(12.50)$ & $40(25.00)$ \\
\hline 4. & Suruhoto & $5709(100.00)$ & $80(50.00)$ & $80(50.00)$ & $160(100.00)$ \\
\hline
\end{tabular}

(Parenthesis indicates percentage to the total)

Table.2 Age group of selected sample respondent

\begin{tabular}{|c|l|c|c|c|}
\hline Sl. No. & \multicolumn{1}{|c|}{ Category } & Adopted & Non-Adopted & Overall \\
\hline 1. & Voter age (up to 16 years) & $0(0.0)$ & $1(0.62)$ & $1(0.62)$ \\
\hline 2. & Young age (17 to 25 years) & $1(0.62)$ & $3(1.88)$ & $4(2.50)$ \\
\hline 3. & Middle age (26 to 35 years) & $10(6.25)$ & $14(8.75)$ & $24(15.00)$ \\
\hline 4. & Mature age (36 to 59 years) & $54(33.75)$ & $40(25.00)$ & $94(58.75)$ \\
\hline 5. & Old age (60 and above) & $15(9.37)$ & $22(13.75)$ & $37(23.12)$ \\
\hline & Total & $80(50.00)$ & $80(50.00)$ & $160(100.00)$ \\
\hline
\end{tabular}

(Parenthesis indicates percentage to the total)

Table.3 Gender wise selected sample respondent

\begin{tabular}{|c|l|c|c|c|}
\hline SI. No. & \multicolumn{1}{|c|}{ Gender } & Adopted & Non-adopted & Overall \\
\hline 1. & Male & $44(27.50)$ & $54(33.75)$ & $98(61.25)$ \\
\hline 2. & Female & $36(22.50)$ & $26(16.25)$ & $62(38.75)$ \\
\hline & Total & $80(50.00)$ & $80(50.00)$ & $160(100.00)$ \\
\hline
\end{tabular}

(Parenthesis indicates percentage to the total)

Table.4 Numbers of Family members in sample household

\begin{tabular}{|c|l|c|c|c|}
\hline Sl. No. & \multicolumn{1}{|c|}{ Category } & Adopted & Non-adopted & Overall \\
\hline $\mathbf{1 .}$ & Up to 3 members & $25(15.63)$ & $16(10.00)$ & $41(25.63)$ \\
\hline $\mathbf{2 .}$ & 4 to 5 members & $44(27.50)$ & $45(28.13)$ & $89(55.62)$ \\
\hline $\mathbf{3 .}$ & 6 to 7 members & $10(6.25)$ & $15(9.37)$ & $25(15.63)$ \\
\hline $\mathbf{4}$. & 8 to 9 members & $1(0.62)$ & $4(2.50)$ & $5(3.12)$ \\
\hline & Total & $80(50.00)$ & $80(50.00)$ & $160(100.00)$ \\
\hline
\end{tabular}

(Parenthesis indicates percentage to the total) 
Table.5 Education level of selected respondent

\begin{tabular}{|c|c|c|c|c|}
\hline SI. No. & Category & Adopted & $\begin{array}{l}\text { Non- } \\
\text { Adopted }\end{array}$ & Overall \\
\hline 1. & Primary (up to 5 class) & $8(5.00)$ & $4(2.50)$ & $12(7.50)$ \\
\hline 2. & Middle (VI to VIII class) & $32(20.00)$ & $25(15.62)$ & $57(35.62)$ \\
\hline 3. & High school (X class) & $25(15.63)$ & $36(22.50)$ & $61(38.12)$ \\
\hline 4. & Intermediate (XII class) & $10(6.25)$ & $5(3.12)$ & $15(9.38)$ \\
\hline 5. & Graduate \& Above & $5(3.12)$ & $10(6.25)$ & $15(9.38)$ \\
\hline & Total & $80(50.00)$ & $80(50.00)$ & $160(100.00)$ \\
\hline
\end{tabular}

(Parenthesis indicates percentage to the total)

Table.6 Land holding of selected sample respondent

\begin{tabular}{|c|l|c|c|c|}
\hline SI. No. & \multicolumn{1}{|c|}{ Category } & Adopted & Non-Adopted & Overall \\
\hline 1. & Small (up to 1.00 ha) & $20(12.50)$ & $25(15.63)$ & $45(28.13)$ \\
\hline 2. & Marginal (1.01 to 2.00 ha) & $45(28.13)$ & $40(25.00)$ & $85(53.12)$ \\
\hline 3. & Medium (2.01 to 4.00 ha) & $10(6.25)$ & $9(5.62)$ & $19(11.88)$ \\
\hline 4. & Large (4 ha and above) & $5(3.12)$ & $6(3.75)$ & $11(6.87)$ \\
\hline \multicolumn{2}{|c|}{ Total } & $80(50.00)$ & $80(50.00)$ & $160(100.00)$ \\
\hline
\end{tabular}

(Parenthesis indicates percentage to the total)

Table.7 Farm experiences of selected sample respondent

\begin{tabular}{|c|c|c|c|c|} 
SI. No. & \multicolumn{1}{|c|}{ Category } & Adopted & $\begin{array}{c}\text { Non- } \\
\text { Adopted }\end{array}$ & Overall \\
\hline 1. & Low (up to 4.00 yrs) & $2(1.25)$ & $6(3.75)$ & $8(5.00)$ \\
\hline 2. & Medium (4.01 to 8.00 yrs) & $34(21.25)$ & $38(23.75)$ & $72(45.00)$ \\
\hline 3. & High (8.01 \& above) & $44(27.50)$ & $36(22.50)$ & $80(50.00)$ \\
\hline & Total & $80(50.00)$ & $80(50.00)$ & $160(100.00)$ \\
\hline
\end{tabular}

(Parenthesis indicates percentage to the total)

Table.8 Occupation of selected sample respondent

\begin{tabular}{|c|l|c|c|c|}
\hline Sl. No. & \multicolumn{1}{|c|}{ Category } & Adopted & $\begin{array}{c}\text { Non- } \\
\text { Adopted }\end{array}$ & Overall \\
\hline 1. & Agriculture only & $35(21.88)$ & $30(18.75)$ & $65(40.63)$ \\
\hline 2. & Business \& Agriculture & $20(12.50)$ & $15(9.38)$ & $35(21.88)$ \\
\hline 3. & Service \& Agriculture & $20(12.50)$ & $35(21.88)$ & $55(34.37)$ \\
\hline 4. & Agriculture, Service \& Business & $5(3.12)$ & $0(0.00)$ & $5(3.12)$ \\
\hline & Total & $80(50.00)$ & $80(50.00)$ & $160(100.00)$ \\
\hline
\end{tabular}

(Parenthesis indicates percentage to the total) 
Table.9 Economic motivation under KVK's programmes in a year

\begin{tabular}{|c|l|c|c|c|}
\hline Sl. No. & \multicolumn{1}{|c|}{ Category } & Adopted & Non-Adopted & Overall \\
\hline $\mathbf{1 .}$ & Low (up to 12) & $45(28.13)$ & $60(37.50)$ & $105(58.33)$ \\
\hline $\mathbf{2 .}$ & Medium (13 to 18) & $25(15.63)$ & $12(7.50)$ & $37(23.13)$ \\
\hline $\mathbf{3 .}$ & High (19 to 24) & $10(6.25)$ & $8(4.44)$ & $18(10.00)$ \\
\hline & Total & $80(50.00)$ & $80(50.00)$ & $160(100.00)$ \\
\hline
\end{tabular}

(Parenthesis indicates percentage to the total)

Table.10 Scientific Orientation under KVK's programmes in a year

\begin{tabular}{|c|l|c|c|c|}
\hline SI. No. & \multicolumn{1}{|c|}{ Category } & Adopted & Non-Adopted & Overall \\
\hline $\mathbf{1 .}$ & Low (6 to 18) & $30(18.75)$ & $60(37.50)$ & $90(56.25)$ \\
\hline $\mathbf{2 .}$ & Medium (19 to 30) & $45(28.13)$ & $18(11.25)$ & $63(39.38)$ \\
\hline 3. & High (31 to 42) & $5(3.13)$ & $2(1.25)$ & $7(4.38)$ \\
\hline & Total & $80(50.00)$ & $80(50.00)$ & $160(100.00)$ \\
\hline
\end{tabular}

(Parenthesis indicates percentage to the total)

Table.11 Source of drinking water facilities by the sample respondent

\begin{tabular}{|c|l|c|c|c|}
\hline SI. No. & \multicolumn{1}{|c|}{ Category } & Adopted & $\begin{array}{c}\text { Non- } \\
\text { Adopted }\end{array}$ & Overall \\
\hline $\mathbf{1 .}$ & No water facilities & $0(0.00)$ & $2(1.25)$ & $0(0.00)$ \\
\hline $\mathbf{2 .}$ & Water connection & $80(50.00)$ & $75(46.88)$ & $160(100.00)$ \\
\hline $\mathbf{3 .}$ & Hand pump & $0(0.00)$ & $1(0.62)$ & $0(0.00)$ \\
\hline $\mathbf{4 .}$ & Diesel / Electric tube well & $0(0.00)$ & $1(0.62)$ & $0(0.00)$ \\
\hline $\mathbf{5 .}$ & Submersible pump & $0(0.00)$ & $1(0.62)$ & $0(0.00)$ \\
\hline & \multicolumn{1}{|c|}{ Total } & $80(50.00)$ & $80(50.00)$ & $160(100.00)$ \\
\hline
\end{tabular}

(Parenthesis indicates percentage to the total)

Table.12 Sources of irrigation water on sample farms

\begin{tabular}{|c|l|c|c|c|}
\hline SI. No. & \multicolumn{1}{|c|}{ Category } & Adopted & Non-Adopted & Overall \\
\hline 1. & No irrigation facilities & $0(0.00)$ & $1(0.62)$ & $1(0.62)$ \\
\hline 2. & River & $80(50.00)$ & $76(47.50)$ & 156 \\
\hline 3. & Canal / Well & $0(0.00)$ & $2(1.25)$ & $2(1.25)$ \\
\hline 4. & Diesel / Electric tube well & $0(0.00)$ & $1(0.62)$ & $1(0.62)$ \\
\hline & \multicolumn{1}{|c|}{ Total } & $80(50.00)$ & $80(50.00)$ & $160(100.00)$ \\
\hline
\end{tabular}

(Parenthesis indicates percentage to the total) 
Table.13 Source of information of different scheme / programmes in a year

\begin{tabular}{|c|l|c|c|c|}
\hline Sl. No. & \multicolumn{1}{|c|}{ Category } & Adopted & Non-Adopted & Overall \\
\hline 1. & Low (up to 6) & $55(34.38)$ & $70(43.75)$ & $125(78.13)$ \\
\hline 2. & Medium (7 to 14) & $20(12.50)$ & $8(5.00)$ & $28(17.50)$ \\
\hline 3. & High (15 \& above) & $5(3.12)$ & $2(1.25)$ & $7(4.38)$ \\
\hline \multicolumn{2}{|c|}{ Total } & $80(50.00)$ & $80(50.00)$ & $160(100.00)$ \\
\hline
\end{tabular}

(Parenthesis indicates percentage to the total)

Table.14 Social participation of selected sample respondent

\begin{tabular}{|c|c|c|c|c|}
\hline SI. No. & \multicolumn{1}{|c|}{ Category } & Adopted & Non-Adopted & Overall \\
\hline 1. & Low (up to 3) & $0(0.00)$ & $2(1.25)$ & $2(1.25)$ \\
\hline 2. & Medium (4 to 6) & $15(9.37)$ & $18(11.25)$ & $33(20.63)$ \\
\hline 3. & High (7 \& above) & $65(40.63)$ & $60(37.50)$ & $125(78.12)$ \\
\hline & Total & $80(50.00)$ & $80(50.00)$ & $160(100.00)$ \\
\hline
\end{tabular}

(Parenthesis indicates percentage to the total)

Table.15 Mass media information of selected sample respondent

\begin{tabular}{|c|l|c|c|c|}
\hline Sl. No. & \multicolumn{1}{|c|}{ Category } & Adopted & Non-Adopted & Overall \\
\hline 1. & Low (up to 2) & $5(3.123)$ & $9(57.25)$ & $14(8.75)$ \\
\hline 2. & Medium (3 to 5) & $15(9.37)$ & $21(13.13)$ & $36(22.50)$ \\
\hline 3. & High (6 \& above) & $60(37.50)$ & $50(31.25)$ & $110(68.75)$ \\
\hline & Total & $80(50.00)$ & $80(50.00)$ & $160(100.00)$ \\
\hline
\end{tabular}

(Parenthesis indicates percentage to the total)

Table.16 Constraint faced by the adopted villages of KVK's in the study areas ( $\mathrm{n}=80)$

\begin{tabular}{|c|c|c|c|c|}
\hline S. No. & Constraints & Number & Percentage & Rank \\
\hline A. & \multicolumn{4}{|l|}{ Technological constraints } \\
\hline 1. & Lack of knowledge about improved varieties & 65 & 81.25 & $\mathbf{I}$ \\
\hline 2. & Non availability of production technology & 56 & 70.00 & II \\
\hline 3. & Lack of training facilities & 38 & 47.50 & III \\
\hline 4. & Lack of improved technologies & 23 & 28.75 & IV \\
\hline B. & \multicolumn{4}{|l|}{ Economic constraints } \\
\hline 1. & Lack of awareness about finance facilities & 63 & 78.75 & $\mathbf{I}$ \\
\hline 2. & Unavailability of finance in time & 52 & 65.00 & II \\
\hline 3. & Fragmentation of land holding & 43 & 53.75 & III \\
\hline 4. & High inputs cost viz; seeds, fertilizers etc & 32 & 40.00 & IV \\
\hline C. & \multicolumn{4}{|l|}{ Institutional constraints } \\
\hline 1. & Lack of training institutes & 50 & 62.50 & $\mathbf{I}$ \\
\hline 2. & Lack of extension services / active workers & 45 & 56.25 & II \\
\hline 3. & Distance between training institution and village & 38 & 47.50 & III \\
\hline D. & \multicolumn{4}{|l|}{ Infra-structural constraints } \\
\hline 1. & Uncertainty about the irrigation water & 65 & 81.25 & $\mathbf{I}$ \\
\hline 2. & Inadequate supply of fertilizers, seeds etc. & 63 & 78.75 & II \\
\hline 3. & Lack of transportation facilities & 49 & 61.25 & III \\
\hline 4. & Lack of marketing facilities & 45 & 56.25 & IV \\
\hline 5. & Lack of machinery / equipments used etc; & 34 & 42.50 & $\mathbf{V}$ \\
\hline 6. & Lack of information system etc & 28 & 35.00 & VI \\
\hline
\end{tabular}


Table 12 reveals that the source of irrigation water facilities availed by the selected sample respondents under KVK's programme in a year in the study areas, as 80 (50.00 per cent) numbers each of respondents were selected from the adopted and non-adopted of KVK's programme in both the categories, out of the total 160 (100.00 per cent) respondents selected for the present study the 80 (50.00 per cent) were enjoying the river facilities as adopted it as cent percentage, while nonadopter 76 (47.50 per cent) were having the facilities of irrigation water, respectively (Mishra et al., 2005).

Table 13 reveals that the source of information of different scheme / programme conducted under the KVK's programme in the study areas, as $80 \quad(50.00$ per cent $)$ numbers each of respondents were selected from the adopted and non-adopted of KVK's programme in both the categories, out of the total 160 (100.00 per cent) respondents selected for the present study the 55 (34.38 per cent) was in low facilities of information as adopted, while non-adopter was 70 (43.75 per cent) were deprived the same.

Table 14 reveals that the social participation of different scheme / programme conducted under the KVK's programme in the study areas, as 80 (50.00 per cent) numbers each of respondents were selected from the adopted and non-adopted of KVK's programme in both the categories, out of the total 160 (100.00 per cent) respondents selected for the present study the 65 (40.63 per cent) was under the high as adopted, while non-adopter was 60 (37.50 per cent) were in same category.

Table 15 reveals that the mass media information of different scheme / programme conducted under the KVK's programme in the study areas, as 80 (50.00 per cent) numbers each of respondents were selected from the adopted and non-adopted of KVK's programme in both the categories, out of the total 160 (100.00 per cent) respondents selected for the present study the 60 (37.50 per cent) was under the high as adopted, while non-adopter was 50 (31.25 per cent) were deprived the same. Similar studies carried out by Dharkre and Sharma (2010).

Table 16 reveals that an attempt is made to identify the constraints faced by the KVK's adopted for adopting the different scheme / programme implemented under different constraints head wise viz; technological, economical, institutional and infra-structural facilities faced by them are presented in the descending order of their relative importance in table. The foremost constraints they faced is technological constraints so the frequency, simple percentage and then it has been ranked using the Garrett's ranking technique and the analytical findings it was found almost similar across various farm size groups so it was recorded as average / overall views. Therefore, constraints are not discussed according to different size groups; the table represents the problems of the sample farmer as a whole. Among the technological constraints prevailed in the study area are the lack of knowledge about improved varieties of different crops faced by the 65 (81.25 per cent) ranked as first, followed by nonavailability of production technology as 56 (70.00 per cent) recorded as second, then lack of training facilities with practical facilities were 38 (47.50 per cent) as third, while 23 (28.75 per cent) were felt there is lack of improved technologies in the study area, respectively. Similar studies carried out by Dharkre and Sharma (2010).

While among the economic constraints prevailed in the study area are due to the lack of awareness about finance facilities available with the different government agencies as 63 (78.75 per cent) ranked as first, followed by 
un-availability of finance facilities in time as 52 (65.00 per cent) recorded as second, then due to the fragmentation of land holding and some practical problems as 43 (53.75 per cent) as third, while 32 (40.00 per cent) were felt there is more problems were due to the high inputs cost viz; seeds, fertilizers etc in the study area, respectively. Similar studies carried out by Sharma et al., (2016).

Due to the institutional constraints prevailed in the study area are in the opinion of due to the lack of training institutes in the block / nearby areas available as 50 (62.50 per cent) ranked as first, followed by lack of extension services / active workers in time as 45 (56.25 per cent) recorded as second, it was found third as 38 (47.50 per cent) were felt there is problems due to travel a lot due to the distance between training institution and ther village in the study area, respectively. Similar studies carried out by (Sharma et al., 2018).

Maximum constraints were recorded on the infrastructural facilities prevailed in the study area are due to the lack of un-certainty about the irrigation water (even rain due to climate change factors) and other agencies as 65 (81.25 per cent) ranked as first, followed by in-adequate supply of fertilizers, seeds etc to the respondents as 63 (78.75 per cent) recorded as second, then the third constraints is due to the lack of transportation facilities as 49 (61.25 per cent), as forth constraints is due to the lack of marketing related facilities 45 (56.25 per cent) were felt there is more problems due to the malpractices and fluctuation of prices due to the imbalance in the demand and supply by the agencies involved in between producer and consumers which may be due the personnel benefit etc; of the agencies involved in the study area, while as 34 (42.50 per cent) were felt there is more problems due to the lack of good quality of machinery / equipments used etc; and also they felt that it is due to the high machinery and equipment cost as fifth in the study area, while 28 (35.00 per cent) were felt this is due to the lack of communication / information system etc; in time, sometime purposely hiding the information if related to some money matters in the study area, respectively.

\section{References}

Ahmad Nafees Singh SP and Parihar P. 2012. Farmer's Assessment of KVK training programme. Economic Affairs. 57(2): 165-168.

Analogous. 2017. Statistical Hand of Nagaland Published by Directorate of Economics and Statistics (various issues), Kohima, Nagaland.

Dhakre, D. S. and Sharma, Amod. 2010. Socio-Economic Development in India. Environment and Ecology. 4(1): 24692472.

Dubey AK Srivastva JP Singh RP and Sharma VK 2008. Impact of KVK training programme on socio-economic status and knowledge of trainees in Allahabad district. Indian Research Journal of Extension Education. 8(2-3): 60-61.

Gaikwad SP Godase SS Tambe BN. 2011. Knowledge gained by farmer by participating in field days organized by K.V.K. Pune. International Journal of Agricultural Sciences. 7(2): 460-461.

Kadam MS Pandya RD Kolgane BT and Khogare DT. 2012. Constraints faced by the experts working at KVK's. Agriculture Update. 7(1-2): 102-164.

Mishra RP Singh AK and Chaudhary RP. 2005. Impact of KVK on farm women development. Farm Science Journal. 14(1): 67-68.

Pongener, Bendangjungla and Sharma, Amod. 2018. Constraints Faced by the Fishery Enterprises: A SWOC Analysis. IJCMAS. 7(5). May: 1595-1603.

Rao NV Ratnakar R and Jain PK. 2012. Impact of farmer field schools in KVK 
adopted villages on level of knowledge and extent of adoption of improved practices of paddy (Oryza sativa L.). Journal of Research ANGRAU. 40(1): $35-41$.

Sharma, A. and Sharma, Anamika. 2008. Problems faced by the farmers in adoption of improved maize cultivation practices in hills. TJRAR. 8(2): 22-23.

Sharma, Amod. 2011. Economic and Constraints of King Chilli Growers in Dimapur District of Nagaland. Journal of Interacademicia. 15(4): 710-719.

Sharma, Amod. 2012. Inter-state Disparities in Socio-economic Development in North East Region of India. Journal of Agricultural Science. 4(9). September: 236-243.

Sharma, Amod. Kichu, Yimkumba and Chaturvedi, B. K. 2016. Economics and Constraints of Pineapple Cultivation in Dimapur District of Nagaland. TJRAR. 16(1). January: 72-75.

Sharma, Amod. Kichu, Yimkumba and Sharma, Pradeep. Kumar. 2018. Sustainable economic analysis and constraints faced by the pineapple growers in Nagaland. Progressive Agriculture. 18(1). February: 27-33.

Shuya, Keviu and Sharma, Amod. 2014. Impact and constraints faced by the borrowers of cooperative bank finance in Nagaland. Economic Affairs. 59(4). October: 561-567.

Shuya, Keviu and Sharma, Amod. 2018. Problems faced by the Borrowers in Utilization and Acquiring of Cooperative Bank Loans in Nagaland. IJED. 14(2). April-June: 52-56.

Singh Dan Singh RP Singh RL and Singh Surat. 2007. Assessment of training programmes of KVK Rampur, its duration and preference time of training programmes. Progressive Research. 2(1-2): 126-128.

Walling, Imti and Sharma, Amod. 2015. Impact of SGRY on beneficiaries and non-beneficiaries in Dimapur district of Nagaland. TJRAR. 15(2). August: 9094.

Walling, Imti. Sharma, Amod. Yadav, Mukesh. Kumar. Rajbhar, Arun, Kumar and Kalai, Kankabati. 2017. Impact of Agricultural Technology Management Agency on Rural Economy of Nagaland, India. Plant Archiver. 17(2). October: 1511-1516.

Yerpude Seema and Khare NK. 2003. Constraints in participation of tribal women in watershed programme. Indian Journal of Extension Education. 3(2): 87-88.

\section{How to cite this article:}

Imsunaro Jamir and Amod Sharma. 2018. Socio-Economic and Constraint Status Assessment of Krishi Vigyan Kendra Training Programmes in Nagaland. Int.J.Curr.Microbiol.App.Sci. 7(11): 1759-1770. doi: https://doi.org/10.20546/ijcmas.2018.711.201 